\title{
On the Operation Mechanism of Finance Companies under Synergistic Controlling
}

\author{
Wenhao Tan \\ School of Accounting \\ Nanjing University of Finance and Economics \\ Nanjing, Jiangsu Province, P. R. China \\ E-mail: twhanenao@163.com
}

\author{
Zhenpeng Ma \\ School of Medical Management \\ Taishan Medical University \\ Taian, Shandong Province, P. R. China \\ E-mail: mazhen7@126.com
}

\begin{abstract}
As a new business operated by enterprise group, finance company is faced with the problem that how to effectively connect with the group headquarters in practice. In this paper, based on the dual perspective of interests coordination and internal control, by using the methods of comparative analysis and logical evolution, from the performance evaluation index system design, business authorization audit mechanism, operation income distribution mechanism and other aspects, the entry point of effective synergistic between the group headquarter and the finance company is discussed, also the author proposes some approaches in order to ensure the smooth implementation of the group's overall strategic target. Furthermore, by using the method of performance evaluation and value creation, in this paper, the author proposes to reconstruct the theoretical framework of the operation control mechanism of the finance company based on the benefit cooperation in group reconstruction. The research conclusion of this paper is helpful for effectively coordinating the interest relationship between financial companies and group member enterprises in fund procurement, which can improve the efficiency of fund allocation within the group.
\end{abstract}

Keywords-Finance Company; Fund allocation; Synergistic; Controlling; Authorization

\section{INTRODUCTION}

Nowadays, large enterprise groups generally adopt the fund-balance center mode for centralized fund management. However, the fund operation function of the fund-balance center is restricted by many policies, and many large enterprise groups are striving to establish finance companies to solve the fund operation problem. However, due to the short development history of finance companies of Chinese enterprise groups, many problems appear in the operation process. Among them, how to coordinate the independent operation of the finance company and financial management and control of the group is a common problem in the operation of the finance companies.

\section{Entry Point of Effective CoOrdinating Operation BETWEEN THE GROUP HEADQUARTERS AND THE FINANCE COMPANY}

As an independent accounting entity, the finance company has some deviation from the group's benefit starting point when making business decisions. The headquarter of the group and the finance company need to coordinate with each other in operation from the aspects of performance evaluation index system design, business authorization audit mechanism and operation income distribution mechanism and so on under the premise that their goals are consistent.

\section{A. Design a Finance Company Performance Evaluation System Based on Overall Value Creation}

In order to give play to the initiative of finance companies in participating in the group's overall coordinated operation, in the performance evaluation of finance companies, it is necessary to increase the assessment of the overall strategic support of the group and reduce the proportion of outbound investment [1]. Meanwhile, it is necessary to distinguish between internal transaction and external transaction of the group. The internal transaction is mainly evaluated from the distribution of credit resources and settlement business handling and other management functions in the group. The external transaction is mainly evaluated from efficiency of investment and finance. The internal transaction is assessed from the perspective of liquidity and turnover frequency of fund operation, while the external transaction is assessed mainly from the perspective of asset appreciation.

\section{B. Introduce the Dual Authorization Mechanism of "Group + Finance Company" in Key Projects}

The group headquarters' control over the finance company is mainly reflected in the analytical evaluation and authorization examination of major investment and financing projects of the group. To be specific, for any investment, financing and asset operation business involving the overall strategy of the company, a joint audit mechanism for the double audit of the headquarters of the group company and the finance company shall be established. In the process of project feasibility evaluation, the Finance Department of the group company mainly carries out the financial feasibility analysis, and then issues the project evaluation plan. After the project investment plan is authorized by the board of directors or the board of shareholders, the Finance Department of the group shall formulate specific financial implementation plan and submit it to the finance company for operation. For the fund operation of key projects, the finance company and the Financial Department of the group need to have countersign to guarantee the safety of fund operation of major projects. 


\section{Establish a Distribution Mechanism for Sharing Project Income between the Group and the Finance Company}

In order to encourage the finance company to actively cooperate with the group in implementing long-term strategies, a revenue sharing mechanism should be established between the group and the finance company. For the emerging industry segment, it is risky for a finance company to offer financial support, and the short-term rate of return is relatively low at the same time, which also has a great impact on financial companies' performance assessment [2]. Therefore, to make up for the finance company's losses in these credit projects, the group company should establish a benefit sharing and distribution mechanism to take the credit funds invested by the finance company into the emerging industry segment as equity investment, and then obtain the future operating income of this segment according to the equity ratio. In this way, finance companies can be more motivated to provide funds and this can also provide e low-cost financing for emerging industry segments.

\section{Reconstruct the Finance Company Management and Control Mechanism Based on the Collaboration STRATEGY}

The independent accounting economic characteristics of the finance company determine that the group headquarters need to establish a set of institutional framework to control the operation of the finance company in line with the implementation of the overall strategy of the group, achieve effective control of the finance company to the maximum extent, and coordinate the consistency between the operational goals of the finance company and the strategic goals of the group.

\section{A. Finance Company's Governance Framework from the Perspective of Clear Rights and Liabilities as Well As Benefit Combination}

As an independent business division of the group's fund operation, the profitability of the finance company is likely to damage the long-term interests of the group as a whole. In order to properly adjust the capital requirements of some projects from the perspective of the overall development strategy of the group, the group company needs to use the control responsibility of the group to correct the operational errors when the interests of the finance company are inconsistent with the overall interests of the group. The control framework of the group headquarters on the finance company is as shown in Fig.1.

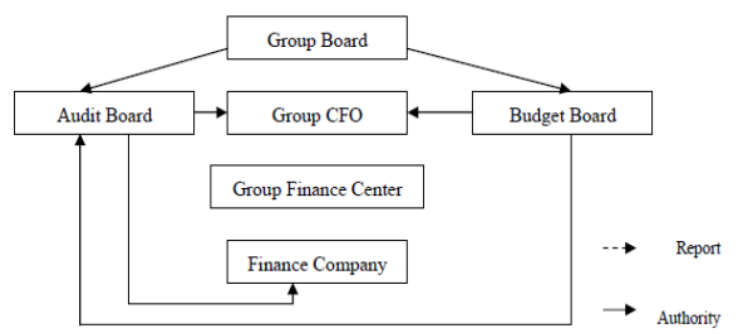

Fig. 1. Control System Diagram of the Group Headquarters on the Finance Company
The board of directors of the group, as the decision maker of the overall strategy of the company, is responsible for the overall planning and decision-making of fund operation [3]. In the daily operations, the budget committee and the audit committee are authorized to examine the feasibility and effectiveness of specific fund operation allocation projects as well as the approval of quota. After being authorized by the audit committee and the budget committee, the CFO of the group is responsible for the specific fund operation plan and providing market-based financial support for the healthy operation of the group member enterprises. The CFO shall monitor the finance company in the whole process before, during and after the event, so as to ensure the efficiency and sustainability of capital allocation and operation. Specifically implemented in the daily fund operation process, the Group Finance Center is responsible for dynamic analysis of the fund operation of the finance company, and timely adjustment and collection of corresponding operational status information feedback to the group headquarters to remind the headquarters to take appropriate corrective measures. Further, in order to monitor the finance company's operation status dynamically, the budget committee, the audit committee and the Group Finance Center should hold joint meetings regularly to conduct systematic inspections on the finance company's fund operation status, risk management, credit granting status and other businesses, discover existing problems and provide specific rectification measures.

\section{B. Implement Hierarchical Operation Mechanism by Relying On the Strategic Control of the Group}

There is internal consistency between the group headquarters and the finance company in terms of fund operation objectives, so it is necessary to give full play to the synergistic effect between them. By contrast, the group headquarters, based on the operational advantages of different business segments, has a wide range of external activity space, so it has stronger negotiation ability than the finance company in communication with the outside world [4]. Therefore, in order to obtain more external financial support, the comparative advantages of the group headquarters and the finance company should be fully utilized. This requires the establishment of a Synergistic framework in which the headquarters and the finance company are matched with each other from the overall level of the group (see Fig. 2).

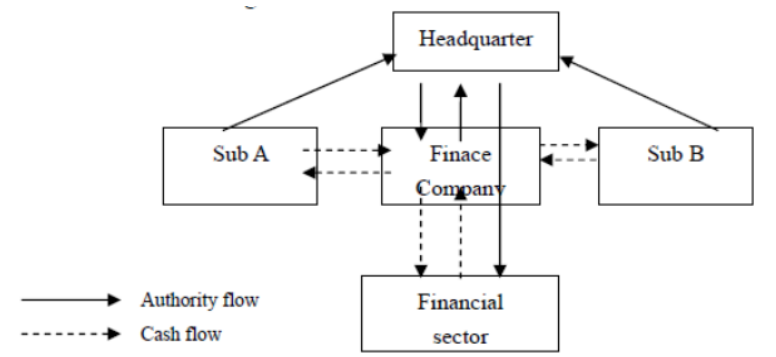

Fig. 2. Synergistic Framework between Group Headquarters and Finance Company

The group headquarters is responsible for unified accommodation of funds with financial institutions. The capital demand plan of the group member enterprises shall be applied 
to the group headquarters directly, and the funds shall be distributed by the group headquarters according to the unified credit granting and demand. The finance company is responsible for allocating the capital in marketing mode according to the fund allocation plan of the group headquarters and the credit status of the member enterprises. The finance company needs to report to the group headquarters on a regular basis to ensure that the direction and benefits of fund allocation are in line with the overall strategic requirements of the group headquarters.

\section{Control Strategy of Finance Companies Based on THE PERSPECTIVE OF SYNERGY}

The control of finance company by the group headquarters is adjustment and control from the strategic level rather than the direct intervention of specific business. Therefore, the implementation of the specific strategic control of the finance company needs to be carried out from the aspects of structure set, permission setting, and personnel allocation of the control organization and so on

\section{A. Simplify the Set of Control Organization}

In order to improve the efficiency of control and avoid unnecessary review and approval and intersecting management, the simplification of the institution setting in the control system should be emphasized. In the business operation audit and control system, the assistant level audit is no longer required, and the audit work is transferred to the Audit Department and Risk Management Committee to complete [5]. In the institution setting process, the management level should be lowered. For the set of the control institution, mainly the three departments, namely finance, audit and internal control committees, as the leading group, are responsible for the specific management and control of the finance company. However, it is worth emphasizing that, although the institutional framework needs to be reduced, the key control points cannot be omitted. The institution setting shall conform to the principle of "high efficiency, simplicity, relevance and containment"; while the number of positions is reduced, the functions shall not be decreased.

\section{B. Set Control Limits Reasonably}

The control of the finance company shall be systematically operated according to different business operation objectives and authorities. A relatively feasible strategy is to classify the business of a finance company according to the level of operational risks, and then set different control authority according to operational risks. Supervising the operation of a finance company according to its authority helps to form an effective balance between efficiency and risk control. The supervision of the finance company mainly focuses on whether the operation of the finance company conforms to the overall interests of the enterprise group, and timely correction shall be made to prevent defects so as to ensure the safety of the asset operation. For things that do not require excessive intervention of the group company, the authorization amount of this kind of business can be increased to give full play to the enthusiasm of the finance company in the fund operation of the group.

\section{Coordinate the Control Personnel and Institutional Allocation}

For the control of a finance company, the quality of asset control depends heavily on the effective implementation of control activities by specific control personnel. Therefore, in the concrete practice of finance company's management and control, scientific allocation of management and control personnel is needed [6]. In this regard, it is necessary to make an overall arrangement from the perspectives of position setting, personnel arrangement, performance evaluation, incentive and constraint mechanisms, and fully consider the impact of position characteristics, corporate culture, interpersonal relationship and hierarchy setting, etc. on the quality of control. The same audit business does not need repeated audit, and the business data information shall be transmitted via the business rule setting and the information sharing mechanism among personnel. The action plan shall be adjusted in time and the highly sensitive early warning mechanism shall be set up to prevent the phenomenon of "collective corruption".

\section{Optimize the Reporting Process}

In conjunction with the staff reduction is the optimization of the internal monitoring reporting process. It is necessary to establish the reporting information sharing mechanism in the monitoring activities of finance companies. In the monitoring activities involving the operation of a single department, parallel information sharing reporting mechanism shall be established, so that the same source information can be effectively shared internally. For monitoring activities involving multiple departments, an information sharing platform shall be established in the system so that the information source can exert diffusion effect to maximum. At the same time, the audit committee and internal control committee of the headquarters of the group shall be promptly informed of the monitoring information obtained in the monitoring activities according to the functional requirements of equal rights and responsibilities. It is particularly important that the group headquarters should establish an automatic information distribution mechanism by relying on the internal information resource platform. For monitoring information of different categories and risk levels, the system should automatically find the target department and distribute information in a timely manner, thus waiting for corresponding authorization and implementation.

\section{CONCLUSION}

Under the background of underdeveloped financial market in China at present, enterprise groups have effectively promoted the development of Chinese enterprises by setting up finance companies to raise funds and allocate funds. As the fund allocation platform of the enterprise group, the finance company needs to clearly define the operation objectives of the group headquarters and the finance company. Based on the overall strategy of the group, an effective coordination and control mechanism is formed between the finance company and the group headquarters, which can maintain the direction and efficiency of internal fund allocation of the group. Under the operation mode of the finance company, the Financial 
Center of the group headquarters should change its functions and become an important carrier for the coordination and control of the group's fund allocation.

\section{REFERENCES}

[1] S. Chang, D. C.Yen, I. Chang and D. Jan, "Internal Control Framework for a Compliant ERP System, Information \& Management”, Vol 51, pp.187-205, 2014.

[2] K. Gugler, E. Peev and E. Segalla, "The Internal Workings of Internal Capital Markets: Cross-Country Evidence”, Journal of Corporate Finance, Vol 20, pp.59-73, 2013.

[3] D. N. Herda, M. A. Notbohm and T. D. Dowdell, "The Effect of External Audits of Internal Control Over Financial Reporting On
Financial Reporting for Clients of Big 4, Second-tier, and Small Audit Firms”, Research in Accounting Regulation, Vol 26, pp.98-103, 2014.

[4] K. C.Miller, T. Y.Proctor, and B.Fulton, “Teaching Managerial Responsibilities for Internal Controls: Perception Gaps between Accounting and Management Professors”, Journal of Accounting Education, Vol 31, pp.1-16, 2013.

[5] W. Shi, R.Wang, “Dynamic Internal Control Performance Over Financial Reporting and External Financing”, Journal of Contemporary Accounting \& Economics, Vol 8, pp.92-109, 2012.

[6] I. Spatacean, “Addressing Fraud Risk by Testing the Effectiveness of Internal Control over Financial Reporting: Case of Romanian Financial Investment Companies”, Procedia Economics and Finance, Vol 3, pp.230-235, 2012. 